\title{
BLENDED LEARNING: MEMBANTU SISWA SMAN 1 ALALAK, KABUPATEN BARITO KUALA MENGEJAR KETERTINGGALAN MATERI PADA MATA PELAJARAN BAHASA INGGRIS SELAMA PANDEMI COVID-19
}

\author{
Hengki, Ratna, Yudha Aprizani
}

Program Studi Pendidikan Bahasa Inggris

Fakultas Keguruan dan Ilmu Pendidikan

Universitas Islam Kalimantan Muhammad Arsyad Al Banjari Banjarmasin

Email : hengkisakkai@yahoo.co.id ; ratnauniskabjm@gmail.com ; yudha.aprizani@gmail.com)

\begin{abstract}
ABSTRAK
Kegiatan ini bertujuan untuk melakukan kegiatan pengajaran kepada siswa SMAN 1 Alalak menggunakan strategi blended learning guna mengejar kertinggalan materi pada mata pelajaran bahasa Inggris selama pandemi COVID-19 sehingga tujuan pembelajaran yang telah ditetapkan dalam kurikulum bisa tercapai, mensosialisasikan strategi pembelajaran berbasis blended learning kepada guru bahasa Inggris dan siswa SMAN 1 Alalak agar mampu menggunakannya dengan baik sehingga kendala dalam proses belajar mengajar dalam jaringan sebagaimana yang terjadi selama pandemi COVID-19 bisa diminimalisir. Khalayak sasaran dalam kegiatan ini adalah siswa di SMAN 1 Alalak. Adapun metode yang digunakan dalam kegiatan pengabdian ini adalah metode seminar dan praktek. Pada metode seminar, tim pelaksana memberikan materi pada mata pelajaran bahasa Inggris yang dianggap tertinggal selama pandemi COVID-19. Sedangkan pada metode praktek, para peserta diminta untuk berbicara dalam bahasa Inggris pada pertemuan dengan menggunakan platform zoom dan juga dalam video. Adapun hasil dari kegiatan ini adalah penggunaan strategi blended learning guna mengejar kertinggalan materi pada mata pelajaran bahasa Inggris selama pandemi COVID-19 berjalan dengan baik dan efektif, penggunaan strategi pembelajaran berbasis blended learning kepada guru bahasa Inggris dan siswa di SMAN 1 Alalak tersosialisasikan dengan baik terutama pada peserta kegiatan pengabdian.
\end{abstract}

Kata Kunci: Blended Learning, Mata Pelajaran, Bahasa Inggris

\section{PENDAHULUAN}

Upaya menggabung metode tradisional dan online dianggap oleh banyak pakar pendidikan sebagai suatu langkah maju dan unggul karena kedua metode itu dapat disinergikan untuk kelansungan sebuah proses pendidikan . Gabungan dua metode ini disebut Blanded Learning (BL). Metode ini sudah lama populer dan ditarapkan di perguruan tinggi umumnya di negaranegara maju. Tapi untuk negara berkembang belum terlalu popular dan dimplementasikan oleh para pendidik. Berhubung pandemik yang merambah ke hampir semua negara berkembang di dunia dan mengabitkan proses pendidikan di sekolah dan kampus tidak 
bisa diselenggarakan secara offline di sisi lain proses pendidikan tersebut harus berjalan terus karena itu adalah kebutuhan oleh semua orang terkhusus anak-anak dan generasi muda untuk kelansungan hidup yang berkualitas. Hal ini tak bedahnya dengan manusia atau hewan yang butuh makan dan minum untuk kelansungan hidupnya.

Beberapa penelitian telah menunjukkan bahwa pendekatan BL dapat meningkatkan keterlibatan siswa dalam pembelajaran dan memberi mereka pengalaman belajar yang baik (Anthony et al. 2020). BL menggeser penekanan dari mengajar ke belajar, memungkinkan siswa untuk menjadi lebih terlibat dan antusias tentang proses pembelajaran, dan dengan demikian meningkatkan ketekunan dan komitmen mereka. Di masa sekarang dan masa depan, BL sangat layak dikembangkan sebagai pendekatan pengajaran terdepan untuk masa depan generasi muda pada dunia Pendidikan.

COVID-19 merupakan suatu penyakit menular yang memberikan dampak yang begitu besar di seluruh dunia (Anthony et al. 2020). Meski dampak yang ditimbulkan tidak semuanya negatif namun bagi dunia pendidikan umumnya di Indonesia dan
Barito Kuala pada khususnya hal ini memberikan dampak negatif yang cukup signifikan. Beberapa hasil riset menunjukkan bahwa proses belajar mengajar di era pandemic COVID-19 memiliki banyak permasalahan (Nurbudiyani Iin, Rahmaniati Rita, Umaternate, Adabiya Radiatul 1967). Setyorini (2020) pada hasil penelitiannya menemukan beberapa kendala yang dialami oleh murid, guru, dan orang tua dalam proses belajar mengajar. Kendala-kendala yang dimaksud yaitu kurangnya penguasaan teknologi, penambahan biaya untuk kuota internet, komunikasi antar siswa menjadi berkurang, adanya pekerjaan tambahan bagi orangtua dalam mendampingi anak dalam belajar, serta jam kerja guru menjadi tidak terbatas. Tentu saja hambatan-hambatan tersebut berpengaruh terhadap capaian dari setiap mata pelajaran yang telah ditentukan. Hasil wawancara yang telah kami lakukan kepada beberapa guru memberikan informasi bahwa pembelajaran dalam jaringan (daring) selama ini dianggap kurang efektif dalam mencapai tujuan pembelajaran pada setiap mata pelajaran tidak terkecuali pada mata pelajaran bahasa Inggris. Oleh karena itu perlu adanya 
suatu strategi yang diharapkan mampu mengatasi permasalahan yang ada. Untuk mengatasi hal tersebut bisa dilakukan dengan cara memadukan proses pengajaran dalam jaringan (daring) dan luar jaringan (luring) yang biasa disebut dengan istilah blended learning.

Menurut Pannen (2005) pembelajaran blended merupakan kombinasi model pembelajaran yang menggunakan pertemuan luar jaringan (luring) dan dalam jaringan (daring). Pada umumnya pembelajaran dalam jaringan adalah asynchronous dimana pengajar/guru/dosen/instruktur dan orang yang diajar tidak bertemu disaat yang sama. Ranganathan, dkk (2007) membagi pembelajaran dalam jaringan (e-learning) ke dalam empat klasifikasi yaitu e-learning tanpa kehadiran dan tanpa komunikasi, e-learning tanpa kehadiran tetapi dengan komunikasi, elearning dikombinasikan dengan kehadiran sesekali, dan yang terakhir elearning digunakan sebagai alat dalam mengajar di kelas

Berdasarkan empat klasifikasi tersebut, kemudian dikembangkan menjadi enam jenis pembelajaran dalam jaringan (e-learning) yaitu pembelajaran tatap muka, pembelajaran mandiri, pembelajaran tidak sinkron, pembelajaran sinkron, blended learning tidak sinkron, dan pembelajaran blended learning singkron. Proses belajar mengajar dalam jaringan bukanlah sesuatu yang buruk namun perlu pemahaman yang mendalam tentang cara penggunaannya. Menurut Herri Sulaiman and Tonah (2020) Di era modern ini proses belajar mengajar dalam jaringan merupakan suatu hal yang mutlak untuk diketahui serta diimplementasikan secara efektif oleh para guru sehingga dampak negatif dari proses belajar mengajar dalam jaringan sebagaimana yang terjadi pada pandemi COVID-19 bisa diminimalisir. Keseringan menggunakan jaringan internet akan memudahkan pemakai untuk menditeksi dan mengatasi internet use problem IUS atau problematika penggunaan internet (Sri.A et al. 2021). Adapun tujuan dari kegiatan ini yaitu melaksanakan kegiatan pengajaran kepada siswa SMA di Kecamatan Alalak Kabupaten Barito Kuala dengan menggunakan strategi blended learning guna mengejar kertinggalan materi pada mata pelajaran bahasa Inggris selama pandemi COVID-19 sehingga tujuan pembelajaran yang telah ditetapkan 
dalam kurikulum bisa tercapai. Selain itu kegiatan ini juga bertujuan untuk mensosialisasikan strategi pembelajaran berbasis blended learning kepada guru bahasa Inggris dan siswa SMA, di Kecamatan Alalak, Kabupaten Barito Kuala. Diharapkan mereka dapat memaksimalkan pembelajaran online sehingga kendala dalam proses belajar mengajar selama pandemic COVID-19 bisa teratasi.

Tujuan utama pengajaran bahasa Inggris yaitu untuk mengembangkan kemampuan siswa menggunakan bahasa Inggris baik lisan maupun tulisan sehingga saat mereka memasuki dunia kerja mereka memiliki kemampuan berkomunikasi berdasarkan empat kemampuan: mendengarkan, berbicara, membaca, dan menulis (Hengki and Ratna 2021). Sebagai tambahan mereka juga berpendapat bahawa Guru dan dosen yang profesional mendambakan peserta didik yang dapat menjadi penulis, pendengar, dan pembicara bahasa asing yang lebih baik.

Pembelajaran bahasa yang efektif didasarkan oleh terjemahan literal yang baik dan penggunaan kata-kata dan struktur yang tidak kaku. Dalam pengajaran bahasa situasional, semua kata dan kalimat sebaiknya berasal dari situasi kehidupan nyata, sehingga siswa dapat menerapkan pengetahuan itu dalam situasi kehidupan sehari-hari.

Komponen Model pembelajaran yang efektif yaitu kualitas pembelajaran dan tingkat pembelajaran yang sesuai. Sedangkan kualitas pembelajaran mengacu pada kegiatan dan tindakan yang direncanakan oleh guru dan siswa, termasuk isi dan pengalaman belajar serta media yang digunakan.

\section{METODE PELAKSANAAN KEGIATAN}

Kegiatan pengabdian ini dilaksanakan dengan beberapa tahapan yaitu:

1. Menganalisa silabus mata pelajaran bahasa Inggris

2. Memberikan tes awal untuk mengetahui kemampuan awal mereka dalam mata pelajaran bahasa Inggris terkait materi yang telah diajarkan selama pandemi COVID19

3. Memeriksa hasil tes awal mereka.

4. Mengajarkan materi pada mata pelajaran bahasa Inggris yang tertinggal selama pandemi COVID19 dengan menggunakan strategi pembelajaran berbasis blended learning dengan melibatkan guru 
bahasa Inggris yang ada di SMAN 1

Alalak, Kabupaten Barito Kuala.

5. Memberikan tes akhir untuk mengetahui efektifitas strategi pembelajaran berbasis blended learning

6. Memeriksa hasil tes akhir para peserta pelatihan

\section{KHALAYAK SASARAN}

Khalayak sasaran dalam kegiatan ini adalah siswa-siswi di SMAN 1 Alalak, Kecamatan Alalak Kabupaten Barito Kuala.

\section{HASIL DAN PEMBAHASAN}

Tes awal dilaksanakan sebelum pengimplementasian strategi blended learning kepada siswa-siswi SMAN 1 Alalak untuk mengetahui kemampuan dasar mereka dalam mata pelajaran bahasa Inggris. Tes tersebut dalam bentuk oral tes dengan tema perkenalan diri. Sylabus pelajaran bahasa Inggris di SMAN 1 Alalak juga berfokus kepada peningkatan keterampilan-keterampilan berbahasa Inggris. Keterampilan yang pertama adalah mendengarkan yaitu memahami berbagai makna interpersonal. Yang kedua adalah berbicara yaitu mengekspresikan berbagai makna interpersonal terutama yang berbentuk deskriptif. Ketiga adalah membaca yaitu memahami ragam makna interpersonal dan tekstual dalam berbagai teks tertulis interaktif dan monologis, terutama dalam bentuk deskriptif, naratif, dan eksposisi. Yang keempat adalah menulis yaitu mengekspresikan berbagai makna interpersonal dan tekstual dalam berbagai teks dan monolog interaktif lisan, terutama yang berbentuk deskriptif dan naratif. Keterampilan berbicara dan memahami makna bacaan menjadi prioritas utama dalam program pengabdian ini. Pelatihan tersebut telah diselenggarakan selama dua bulan dan sukses mengatasi ketertinggalan materi pada mata pelajaran bahasa Inggris selama pandemi COVID-19 di SMAN 1 Alalak, Kabupaten Barito Kuala.
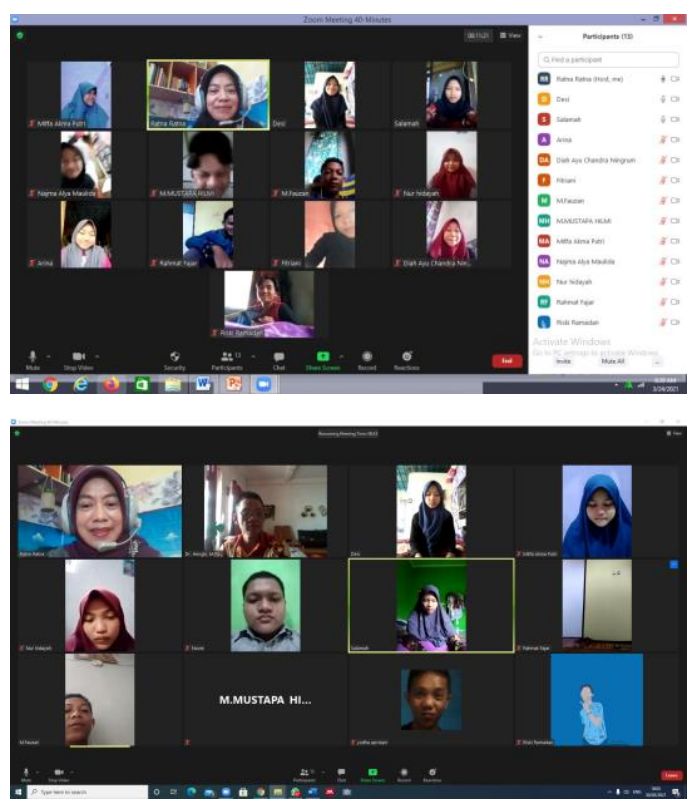
Motivasi belajar bahasa Inggris siswa-siswi SMAN 1 Alalak meningkat selama mengikuti pelatihan. Hal itu terlihat dari self-confidence mereka ketika berbicara serta keseriusan mereka belajar online melalui aplikasi Zoom, mengirim video-video praktek berbicara dan mengumpul tugas-tugas reading dan writing melalui aplikasi google classroom.

Nilai tes akhir lebih tinggi dibandingkan dengan nilai tes awal. Dari data tersebut menunjukan bahwa strategi pembelajaran blanded learning dalam belajar bahasa Inggris di masa COVID-19 bisa terlaksana dan memberi hasil yang baik kepada siswa-siswi SMAN 1 Alalak.

Berdasarkan hasil tes kepada seluruh peserta kegiatan pengabdian pada masyarakat yang dilaksanakan pada bulan Maret sampai dengan bulan Mei 2021 melalui aplikasi google classroom, whatsApp, dan aplikasi Zoom menunjukkan nilai rata-rata siswa pada tes akhir lebih baik dibandingkan nilai rata-rata mereka pada tes awal. Untuk lebih jelasnya dapat dilihat dari chart berikut ini:

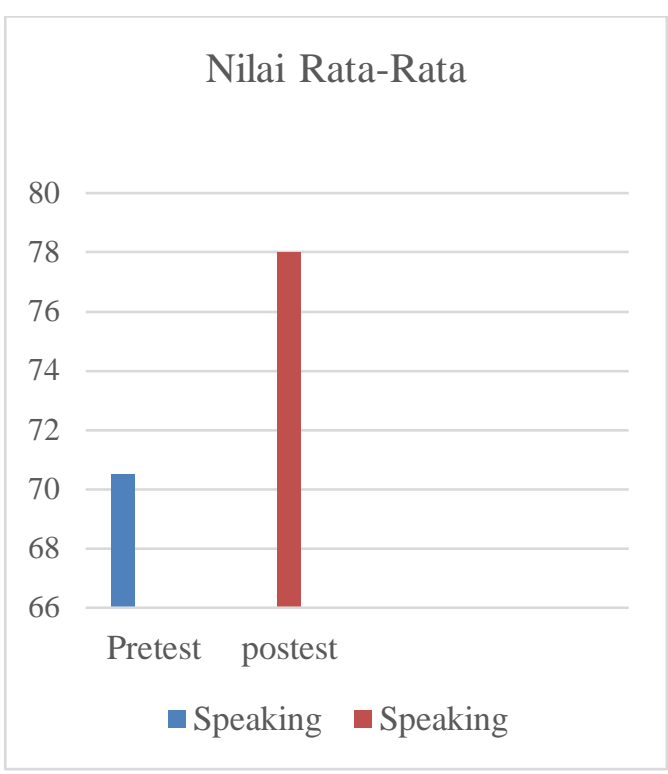

Chart tersebut menunjukkan bahwa nilai rata-rata siswa SMAN 1 Alalak pada keterampilan berbicara yaitu nilai 78 pada hasil posttest dan 70,5 pada hasil pretest. Dari uraian tersebut diketahui bahwa nilai postest lebih baik daripada nilai pretest maka dapat dinyatakan bahwa:

1. Pengajaran dengan blanded learning di SMAN 1 Alalak, Kabupaten Barito Kuala sebagai upaya mengejar ketertinggalan materi pada mata pelajaran bahasa Inggris selama COVID-19 berjalan dengan baik dan efektif.

2. Ketertinggalan materi pada mata pelajaran bahasa Inggris di SMAN 1 Alalak, Kabupaten Barito Kuala dapat teratasi.

3. Motivasi belajar bahasa Inggris siswa(i) SMAN 1 Alalak, Kabupaten 
Barito Kuala semakin meningkat.

Hal itu terlihat dari self-confidence mereka ketika berbicara serta keseriusan dalam menghafal kosa kata.

Ditinjau dari kelembagaan, UNISKA yang merupakan salah satu universitas yang memiliki program studi pendidikan bahasa Inggris pada Fakultas Keguruan dan Ilmu Pendidikan akan dapat menjadi rujukan bagi para siswa(i) SMAN 1 Alalak, Kabupaten

\section{KESIMPULAN}

Dari kegiatan pengabdian yang telah kami laksanakan dapat disimpulkan bahwa penggunaan strategi blended learning guna mengejar kertinggalan materi pada mata pelajaran bahasa Inggris selama pandemi COVID-19 berjalan dengan baik dan efektif. Hal tersebut terlihat dari hasil analisa data tes awal dan tes akhir yang memperlihatkan perbedaan yang cukup baik dimana nilai rata-rata pada hasil tes akhir lebih tinggi dibandingkan nilai rata-rata pada tes awal. Selain hal tersebut di atas tim juga dapat menarik kesimpulan bahwa penggunaan strategi pembelajaran berbasis blended learning kepada guru bahasa Inggris dan siswa di SMAN 1 Alalak tersosialisasikan dengan baik terutama pada peserta kegiatan pengabdian.

\section{DAFTAR PUSTAKA}

Afrian, Ramdan. 2014. Pengaruh Pembelajaran Blended Learning terhadap Hasil Belajar Siswa SMA. Tesis. Pendidikan Geografi, Pascasarjana Universitas Negeri Malang

Astuti, Herlina, Yuli. 2014. The Use of Blended Learning through Facebook to Improve Students' Writing Ability. Thesis. Graduate Program in English Language Teaching, State University of Malang

Almberek, H. (2002) "E-learning: to develop the lecture method in university education using elearning with a proposed model,", A working paper submitted to the School of the Future Symposium, King Saud University

Abadi, M (2002.) E-learning and traditional education: what is the difference?" Al Maerefah, vol. 36, no. 91, pp. 18-23,

Setyorini. 2020. Pandemi COVID-19 dan Online Learning: Apakah Berpengaruh Terhadap Proses Pembelajaran Pada Kurikulum 13?. Journal of Industrial Engineering \& Management Research (JIEMAR) Volume 01 Nomor 01 Juni 2020, Halaman 95-102.

Codone $\quad S \quad$ (2001). Codone, An ELearning Primer, Mercer University, Macon, GA, USA, http://faculty.mercer.edu/codone_ s/elearningprimer.PDF. , An ELearning Primer, Mercer University, Macon, GA, USA, 
2001, http://faculty.mercer.edu/co done_s/elearningprimer.PDF.

Wasis D. Dwiyogo. 2018. Pembelajaran Berbasis Blended Learning. Rajawali Press

Bosman, K. (2002) Simulation-based elearning, Syracuse University, ASTD Presentation, Syracuse, NY, USA, http://home.stny.rr.com/bosman/i de600presentation.html.

Anthony, Bokolo, Adzhar Kamaludin, Awanis Romli, Anis Farihan Mat Raffei, Danakorn Nincarean A.L.Eh Phon, Aziman Abdullah, and Gan Leong Ming. 2020. Blended Learning Adoption and Implementation in Higher Education: A Theoretical and Systematic Review. Technology, Knowledge and Learning. Springer Netherlands. https://doi.org/10.1007/s10758020-09477-z.

Hengki, and Ratna. 2021. "STRATEGI PENGAJARAN IMMERSION: MENINGKATKAN KETERAMPILAN BERBAHASA INGGRIS
REMAJA MESJID DESA SEMANGAT DALAM, KECAMATAN ALALAK KABUPATEN BARITO KUALA Hengki" 6 (April).

Herri Sulaiman, Trusti Hapsari, Tonah, dan Fuad Nasir. 2020. "Simulasi Aplikasi Tryout Ujian Nasional Berbasis Komputer (Unbk) Online Di Sma Kabupaten Cirebon." Jurnal Pengabdian AlIkhlas 6: 138-47.

Nurbudiyani Iin, Rahmaniati Rita, Umaternate, Adabiya Radiatul, Hafid Istiqamah. 1967. "KETAHANAN KELUARGA DALAM MENGHADAPI PANDEMI COVID-19 DAN PASKA COVID-19 DI KELURAHAN SABARU KALIMANTAN TENGAH Iin." Angewandte Chemie International Edition, 6(11), 951-952. 6 (April): 429-35.

Sri.A, Hayati, Haryadi Rudi, Aminah, and Prasetia Muhammad E. 2021. "PARENTING COACHING MENGATASI PROBLEMATIC INTERNET USE" 7: 33-47. 